\section{Summary points}

Huntington's disease is an autosomal dominant, lethal neurodegenerative disorder with an average age of onset of 37 years. There is no cure and or current preventive treatment

Predictive genetic testing and prenatal diagnosis are available for Huntington's disease

Guidelines recommend that prenatal tests should be provided only when termination of pregnancy is planned in the event of a positive test result

Offering prenatal diagnosis to parents who have no desire to terminate their pregnancy is controversial

decision. The ultimate decisions should be those of the parents, not their clinicians.- RED, BF

\section{Discussion}

Requests for prenatal tests are likely to become more common as genetic knowledge continues to increase. The case we present highlights the ethical challenges and the contradictory views that professionals may hold.

There are four key ethical issues for clinical practice. Firstly, and in our view most importantly, how should the autonomy of parents be balanced with the future autonomy of their unborn children? Secondly, is it paternalistic for a clinician to refuse to administer a prenatal test requested by a woman (or a couple) and, if so, is such paternalism ever acceptable? Thirdly, is it appropriate for clinical guidelines to make recommen- dations that may encourage patients to lie to achieve a desired test or treatment? Finally, does it constitute a breach of confidentiality when parents are informed about genetic characteristics of their unborn child? These ethical issues provide a basis for consideration by clinicians faced with similar requests for prenatal testing in the future.

We thank Richard Ashcroft for his helpful comments and insight.

Contributors and sources: RED is a postdoctoral researcher who undertook $\mathrm{PhD}$ studies on ethical aspects of predictive genetic testing in minors. $\mathrm{BF}$ is undertaking a $\mathrm{PhD}$ in ethics. MBD is a medical geneticist who specialises in neurogenetics and has research interest in genetic testing of minors. MBD is an NHMRC Practitioner Fellow.

Funding: None.

Competing interests: None declared.

1 Myers R, Marans K, MacDonald M. Huntington's disease. In: Wells R, Warren S, eds. Genetic instabilities and hereditary neurological diseases. San Diego: Academic Press, 1998:301-23.

2 International Huntington Association and the World Federation of Neurology Research Group on Huntington's Chorea. Guidelines for the molecular genetics predictive test in Huntington's disease. J Med Genet 1994;31:555-9.

3 Clinical Genetics Society. The genetic testing of children. Working party of the Clinical Genetics Society (UK). J Med Genet 1994:31:785-97.

4 American Society of Human Genetics Board of Directors, American College of Medical Genetics Board of Directors. Points to consider: ethiCollege of Medical Genetics Board of Directors. Points to consider: ethi-
cal, legal and psychosocial implications of genetic testing in children and adolescents. Am J Hum Genet 1995;57:1233-41.

5 Human Genetics Society of Australasia. Predictive testing in children and adolescents (version 2, April 2005). www.hgsa.com.au/ (accessed Aug 2005).

6 Duncan RE, Savulescu J, Gillam L, Williamson R, Delatycki MB. An international survey of predictive genetic testing in children for adult onset conditions. Genet Med 2005;7:390-6.

7 Tolmie J, Davidson H, May H, McIntosh K, Paterson J, Smith B. The prenatal exclusion test for Huntington's disease: experience in the west of Scotland, 1986-1993.J Med Genet 1995;32:97-101.

8 Wiggins S, Whyte P, Huggins M, Adam S, Theilmann J, Bloch M, et al. The Wiggins S, Whyte P, Huggins M, Adam S, Theilmann J, Bloch M, et al. The
psychological consequences of predictive testing for Huntington's disease. Canadian Collaborative Study of Predictive Testing. N Engl J Med 1992;327:1401-6.

(Accepted 17 August 2006)

doi $10.1136 /$ bmj.38950.645799.55

\title{
Evidence based medicine
}

\section{Analogies between reading of medical and religious texts}

\author{
Matthew Links
}

Whether you take a fundamental or liberal view of scientific evidence will affect how you interpret it. But just as with religion, we need to admit there will be legitimate differences in our views

Cancer Care Centre, University of New South Wales Clinical School, St George Hospital, Kogarah, NSW 2217, Australia Matthew Links director

Matthew.Links@ sesiahs.health. nsw.gov.au

BMJ 2006;333:1068-70
Conventional medicine can be seen as a belief system characterised by a profession of faith in evidence based medicine. ${ }^{1}$ Faith in evidence based medicine follows from the benefits it has delivered in the past and continues to deliver. It is the best method we have for navigating our way through potential new treatments. ${ }^{1}$

Evidence based medicine, analogous to many religious traditions, is a system for the interpretation of a canon of sacred texts (medical literature). Differences in interpretation can often be traced to different assumptions underlying our reading of the literature. Just as there are fundamentalist, conservative, and liberal views of religious texts there are similar views of evidence based medicine. An examination of these views and assumptions can tell us much about differences in medical opinion.

\section{Religious fundamentalism}

The Oxford dictionary defines fundamentalism as the strict maintenance of the ancient or fundamental doctrines of any religion or ideology. ${ }^{2}$ Fundamentalism sees truth as unified, revealed, absolute, and inerrant. Supporters have a black and white view, seeing themselves as the true keepers of the faith with good reason for an absolute belief that they are right. Critics 


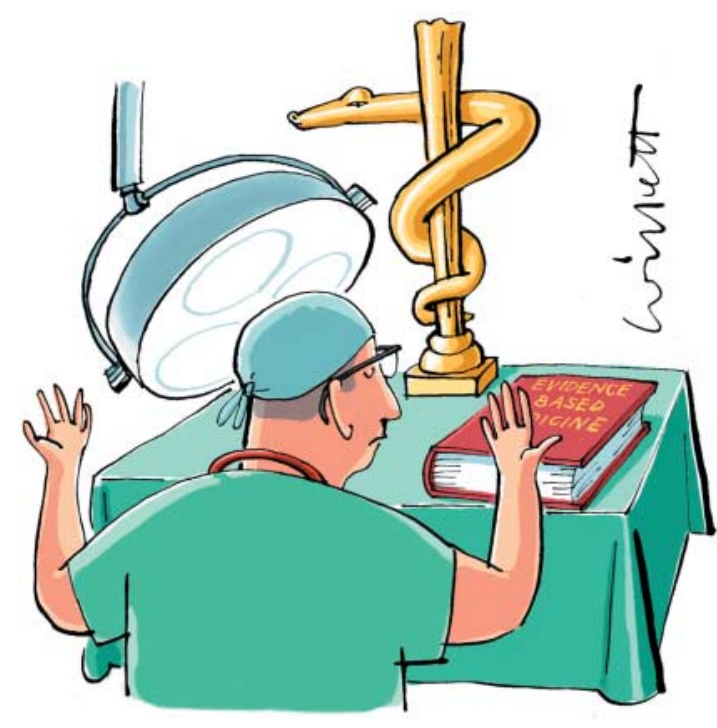

see the world in shades of grey and view fundamentalism as self righteous and simplistic.

Fundamentalism is associated with literal readings of sacred texts. Texts can be interpreted in different ways. A liberal reading of biblical prohibitions of homosexuality, for example, might consider that they do not apply to contemporary committed same sex relationships. Thus people with the same basic belief system, reading the same text, can come to radically different conclusions. These differences derive from the varying assumptions they bring to reading and applying the literature.

\section{Medical fundamentalism}

Variation in interpretation of the medical literature shares many of the features of variations in interpretation of religious texts. Proponents of evidence based medicine emphasise important principles of a balanced view. ${ }^{3}$ This emphasises the limitations of evidence based medicine, ${ }^{4}$ the need for judgment in applying it to individual patients, ${ }^{5}$ and the validity of evidence other than randomised controlled trials. ${ }^{67} \mathrm{~A}$ liberal approach goes beyond this. It sees the literature as a guide, establishing principles that need to be applied to specific situations.

Fundamentalists, however, take a strict and literal view of the literature. They give little allowance for individualisation, show little scepticism about the limitations of the literature, and tend to undervalue non-randomised evidence. ${ }^{3}$ The fundamentalist approach sees the literature as law, a series of "sacred texts" that are treated with great respect and are to be applied literally. Any deviation from the text is seen as heresy. Just like religious fundamentalists, medical fundamentalists tend to be self righteous and denigrate other interpretations. Of course, the analogy between medicine and religion is not to be taken too far. Violence or fanaticism are not features of most medical decision making.

\section{Examples of relevant questions}

Deviation from good evidence based practice is an important reason for poor outcomes in many aspects of life. In the medical domain, issues of interpretation greatly affect the treatments that we recommend. There is often controversy, conflict, and heated discussion about medical decisions. Below I give some examples of controversies in oncology with a conservative and liberal view of the literature. Similar issues apply in other disciplines.

\section{Can we extrapolate evidence from one drug to another?}

This is a fundamental question in evidence based medicine. ${ }^{8}$ Trials provide evidence on specific drugs, yet we often deal with classes (or groups) of drugs with similar efficacy. Does the evidence apply only to the drug tested? Are trials recipes for treatment or proof of principle? For example, we know from a meta-analysis and a large randomised controlled trial that adjuvant chemotherapy for early non-small cell lung cancer offers a small survival advantage (4-5\%). Does this provide proof that adjuvant chemotherapy works or that specific drugs work. It takes a long time to conduct such trials, and the drugs used have largely been replaced by combinations that have been shown to be more effective in advanced disease. ${ }^{9}$ It is tempting to substitute more contemporary regimens, and this has become standard practice in many countries. Is this liberal view an improvement in patient care, allowing use of less toxic or more efficacious regimens, or a deviation from the evidence to support chemotherapy in this setting?

\section{Do we apply treatments exactly as they were prescribed in a clinical trial?}

Chemotherapy drugs often enter clinical practice with little information about optimal dosing. The doses deliverable in community practice are often less than those used in the registration trials. This experience is supported by respected guidelines, such as those of the British Columbia Cancer Agency, which recommend reduced dose intensities of topotecan, vinorelbine, and capecitabine. ${ }^{10}$ Such a practice is safe and rational but causes problems because the dose no longer corresponds to that in the efficacy trial. In some cases, low level evidence provides some support for the efficacy of lower doses, ${ }^{11}$ but is this enough?

The recommended dose for irinotecan for metastatic colorectal cancer is $350 \mathrm{mg} / \mathrm{m}^{2}$, but in one trial $63 \%$ of patients developed grade $3 / 4$ toxicity and $30 \%$ of patients were admitted to hospital for a median duration of nine days..$^{12}$ The dose actually delivered is therefore much less than $350 \mathrm{mg} / \mathrm{m}^{2}$. Is it justifiable to prescribe a lower dose, and increase it in the absence of toxicity, in order to avoid a high level of initial toxicity? Prescribing unrealistic doses that require frequent omissions of doses or dose reductions is inefficient. It is disruptive to patients and staff. But should we take a conservative view and adhere to the treatment as delivered in the randomised trial?

\section{How much evidence is enough?}

Few advances in oncology offer cure of conditions that have previously had only palliative treatments. One such advance has been peritonectomy and hyperthermic intraperitoneal chemotherapy for peritoneal metastases from metastatic colorectal cancer. ${ }^{13}$ The well conducted randomised controlled trial was stopped early because the experimental treatment had 
a considerable advantage over conventional palliative treatment. The findings are supported by unrandomised data strongly suggesting that this treatment cures some patients. ${ }^{14}$ This trial has generated divergent responses. Because of the small size, the difference in survival relates to a small number of patients. Some will demand a confirmatory trial to prove the principle. An ethical trial requires equipoise, a difficult assumption with a trial that has strongly positive results. How much evidence is enough?

\section{How do we apply data from trials to patients in the community?}

Randomised controlled trials show a consistent improved survival (of three months) in patients with locally advanced non-small cell lung cancer who have concurrent rather than sequential chemo-irradiation. This has led to guidelines recommending concurrent treatment. ${ }^{15} 16$ The toxicity in these trials was substantial. The main difficulty in applying these data is the external validity. We know that most patients with this cancer have comorbidity, often chronic airflow limitation and vascular disease. We know that most patients are elderly and were not well represented in the clinical trials. ${ }^{17}$ How then should we treat patients with serious comorbidity and locally advanced non-small cell lung cancer who would not have been eligible for the reference trials? If we exclude these patients from combined treatment because of concerns about toxicity, what level of comorbidity do we use to make the decision?

\section{Conclusions}

Evidence based medicine and the scientific medical literature are the bedrock of modern medical practice. The above questions show that interpretation of the evidence is not clear cut. Just as in the religious literature, different world views result in varying interpretations. A person with a more fundamentalist orientation is much more likely to stay within the letter of the law. A more liberal perspective would result in important deviations from the evidence.

The advantage of the conservative position is that it is clear and well defined. If you allow a large degree of latitude to interpretation, where does it stop? The advantage of the liberal position is that it is flexible. The examples above suggest the possibility of delivering better outcomes in terms of reduced toxicity, increased efficacy, reduced cost, or improved convenience.

We all need to realise that differences in interpretation of the medical literature often relate to different assumptions about the way we view these texts. There is good interpretation and bad interpretation, but sometimes the reason for disagreement is that we bring equally valid but different views to the text. One of the difficulties of debate in both the religious and medical context is that attitudes tend to become polarised. We need to be aware of our differing assumptions, avoid self righteousness, and conduct these discussions in an atmosphere of tolerance.

Contributors and sources: ML is a medical oncologist in clinical practice with an interest in lung cancer and intraperitoneal chemotherapy. This article has arisen out of discussions of evidence conducted with colleagues in a project to standardise

\section{Summary points}

Belief systems in medicine are analogous to those of religious traditions

Attitudes to medical or religious literature can be characterised as fundamentalist, conservative, or liberal

Variations between these world views reflect different ways of reading evidence not a disparity in the value placed on the evidence

Debates on evidence need to acknowledge the validity of alternative world views

chemotherapy protocols in New South Wales and controversy over the role of peritonectomy for metastatic colorectal cancer. He describes himself as having a liberal world view in relation to medical evidence and Christianity.

Competing interests: ML has accepted travel grants to attend conferences from AstraZeneca, Aventis, Eli-Lilly, Pierre Fabre, and Sanofi-Synthelabo. He has research funding and has worked as a consultant for Eli-Lilly. He is involved in a funding application for research on peritonectomy.

1 Group TE-BMW. Evidence-based medicine: a new approach to teaching the practice of medicine. JAMA 1992;268:2420-5.

Oxford University Press. AskOxford.com. (accessed 6 Aug 2006).

3 Loefler I. Evidence based medicine. BMJ 2004;328:842.

Julian DG. What is right and what is wrong about evidence-based medicine? J Cardiovasc Electrophysiol 2003;14(9 Suppl):S2-5.

5 Schattner A, Fletcher RH. Research evidence and the individual patient. OJM 2003;96:1-5.

6 Green J, Britten N. Qualitative research and evidence based medicine. BMJ 1998;316:1230-2.

7 Devereaux PJ, Yusuf S. The evolution of the randomized controlled trial and its role in evidence-based decision making. I Intern Med 2003;254(2):105-13.

8 Antman EM, Ferguson JJ. Should evidence-based proof of efficacy as defined for a specific therapeutic agent be extrapolated to encompass a therapeutic class of agents?. Circulation 2003;108:2604-7.

9 Socinski MA. Cytotoxic chemotherapy in advanced non-small cell lung cancer: a review of standard treatment paradigms. Clin Cancer Res 2004:10(12):4210-14s.

10 British Columbia Cancer Agency. Chemotherapy protocols. British Columbia Cancer Agency. Chemoth
www.bccancer.bc.ca/default.htm (accessed 6 Sep 2006).

11 Rose PG, Maxson JH, Fusco N, Mossbruger K, Rodriguez M. Liposomal doxorubicin in ovarian, peritoneal, and tubal carcinoma: a retrospective comparative study of single-agent dosages. Gynecol Oncol 2001;82:323-8.

12 Fuchs CS, Moore MR, Harker G, Villa L, Rinaldi D, Hecht JR. Phase III comparison of two irinotecan dosing regimens in second-line therapy of metastatic colorectal cancer. J Clin Oncol 2003;21:807-14.

13 Verwaal VJ, van Ruth S, de Bree E, van Sloothen GW, van Tinteren H, Boot $\mathrm{H}$, et al. Randomized trial of cytoreduction and hyperthermic intraperitoneal chemotherapy versus systemic chemotherapy and palliative surgery in patients with peritoneal carcinomatosis of colorectal cancer. $J$ Clin Oncol 2003:21:3737-43.

14 Glehen O, Kwiatkowski F Sugarbaker PH, Elias D, Levine EA, De Simone $\mathrm{M}$, et al. Cytoreductive surgery combined with perioperative intraperitoneal chemotherapy for the management of peritoneal carcinomatosis from colorectal cancer: a multi-institutional study. J Clin Oncol 2004:22:3284-92

15 Jett JR, Scott WJ, Rivera MP, Sause WT, American College of Chest Physicians. Guidelines on treatment of stage IIIB non-small cell lung cancer. Chest 2003;123(1 Suppl):221-5s.

16 Australian Cancer Network Management of Lung Cancer Guidelines Working Party. Clinical practice guidelines for the prevention, diagnosis and management of lung cancer. Canberra: National Health and Medical Research Council of Australia, 2004.

17 Vardy JL, Boyer MJ, Beale P, Barnes D, Clarke SJ. Patients in advanced non small cell lung cancer (ANSCLC) chemotherapy trials are not representative of the general lung cancer population [abstract 2668]. Proc Am Soc Clin Oncol 2003;22:663.

(Accepted 25 August 2006)

doi $10.1136 /$ bmj.38966.487350.68 